\title{
Variation of phenotype in patients with glucocorticoid remediable aldosteronism
}

\author{
L J Gates, A A MacConnachie, R P Lifton, N E Haites, N Benjamin
}

\begin{abstract}
Glucocorticoid remediable aldosteronism (GRA), an autosomal dominant cause of primary aldosteronism, has been described as resulting in severe hypertension with premature death from stroke. We describe two new large pedigrees which include subjects who have the abnormal chimaeric gene strongly linked to GRA. The majority of affected members, who have only mild hypertension and normal biochemistry, are clinically indistinguishable from patients with essential hypertension. It is therefore likely that this condition is underdiagnosed.

( $\mathcal{}$ Med Genet 1996;33:25-28)
\end{abstract}

Key words: hypertension; hyperaldosteronism; hypokalaemia.

Glucocorticoid remediable aldosteronism (GRA) is a rare autosomal dominant ${ }^{1}$ cause of primary aldosteronism originally described in 1966 by Sutherland $e t a l^{2}$ in a father and son with hypertension, low plasma potassium concentration, increased aldosterone secretion, increased plasma volume, and suppressed plasma renin activity, all of which were found to be reversed by low dose dexamethasone therapy. Further cases have been described of severe hypertension usually presenting at a young age with signs of primary aldosteronism correctable by glucocorticoids and in association with familial occurrence of hypertension ${ }^{3-6}$ and of cerebral haemorrhage. ${ }^{56}$ More recently the association of GRA with high levels of the abnormal hybrid steroids 18-hydroxycortisol ${ }^{7}$ and 18-oxocortisol ${ }^{8}$ has been reported.

We describe two pedigrees in which a total of 29 patients have been identified as possessing the abnormal $6.3 \mathrm{~kb}$ genomic DNA fragment, following restriction analysis and detected by Southern blotting, which is tightly linked to GRA. ${ }^{9}$ In normal subjects, when genomic DNA is digested with the restriction enzyme $B a m H I$, Southern blotted, and probed with a $11 \beta$-hydroxylase specific probe, there are two bands on the resultant autoradiograph of 8.5 and $4.5 \mathrm{~kb}$, corresponding to $11 \beta$-hydroxylase and aldosterone synthase respectively.

Aldosterone synthase and $11 \beta$-hydroxylase are $>90 \%$ homologous at the nucleotide sequence level and both lie in tandem on chromosome 8q. ${ }^{10}$ When genomic DNA from affected subjects is examined, the presence of a chimaeric gene results in a restriction fragment length polymorphism (fig 1) and a third band on the autoradiograph (fig 2 ). This new 6.3 kilobase fragment results from the presence of a chimaeric gene in which the regulatory sequences of $11 \beta$ hydroxylase are fused to the coding sequences of aldosterone synthase ${ }^{11}$ (fig 3 ). The product of this gene would therefore have aldosterone synthase activity within the zona fasciculata because of the specificity of its regulatory sequences and would result in the synthesis of 18-oxocortisol, 18hydroxycortisol, and aldosterone regulated in response to adrenocorticotrophic hormone (ACTH). Miyahara et $a^{12}$ have shown that the protein encoded cDNA corresponding to the chimaeric GRA gene exhibits aldosterone synthase activity. In patients with GRA, treatment with glucocorticoids causes feedback suppression of ACTH by its effect on the anterior pituitary, reducing aldosterone, 18-hydroxycortisol, and 18-oxocortisol synthesis. ${ }^{13}$

\section{Case reports}

FAMILY A

The proband $(\mathrm{V} \cdot 21$, fig 4$)$, a 55 year old farmer from Huntly, was first found to be hypertensive (blood pressure $220 / 150 \mathrm{mmHg}$ ) at the age of 15 when he presented to his general practitioner with malaise. Evidence of sequelae of hypertension were apparent with ECG evidence of left ventricular hypertrophy with strain pattern, left ventricular enlargement on chest $x$ ray, and grade 3 hypertensive retinopathy. Serum sodium, potassium, and bicarbonate were initially within the normal range and there was no evidence of renal disease by intravenous pyelography or renal biopsy. However, during the initial inpatient assessment, there was a tendency to hypokalaemia with serum potassium recorded as $3 \cdot 3,3 \cdot 1$, and $3 \cdot 8 \mathrm{mmol} / 1$ (NR $3 \cdot 5-4.9 \mathrm{mmol} / \mathrm{l}$ ). A strong maternal family history of hypertension was also noted with his mother (IV·17), grandmother (III.8), and two uncles (IV·12 and IV 18 ) being hypertensive and, in addition, on examination one of his sisters $(\mathrm{V} \cdot 22)$, aged 23 , was also found to be hypertensive. There was also a history of cerebral haemorrhage in his maternal grandmother.

The proband had poor control of his blood pressure for many years while taking multiple antihypertensive medications and required several admissions to hospital. He had previously

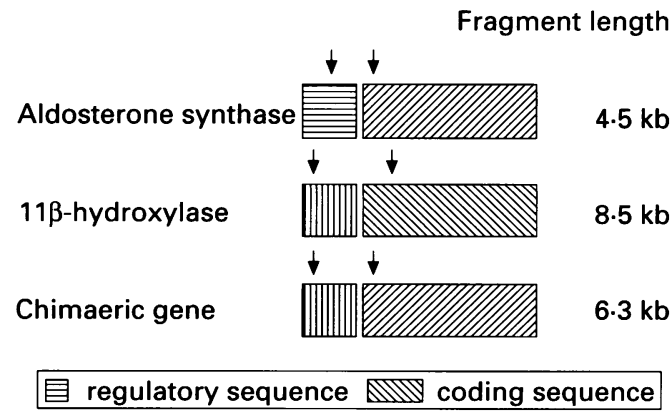

Figure 1 Schematic representation of BamHI restriction sites to show the restriction fragment length polymorphism present in DNA from patients with the chimaeric gene. 


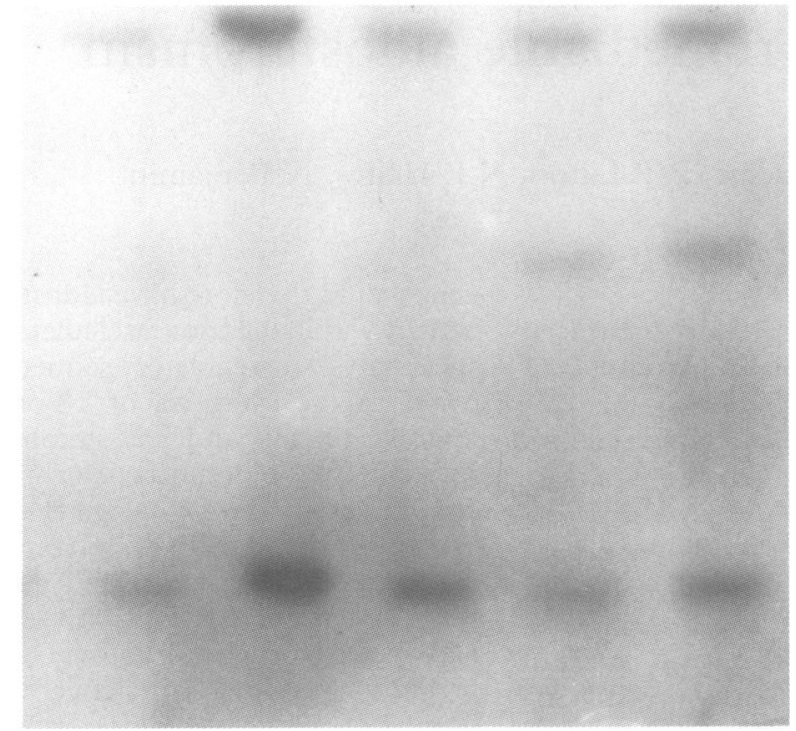

Figure 2 Autoradiograph of BamHI digested DNA with an 11 $\beta$-hydroxylase exon 3-5 probe. GRA mutation positive subjects have a third $6 \cdot 3 \mathrm{~kb}$ band corresponding to the presence of the chimaeric gene as well as the $8.5 \mathrm{~kb}$ band and 4.5 band corresponding to $11 \beta$-hydroxylase and aldosterone synthase respectively.

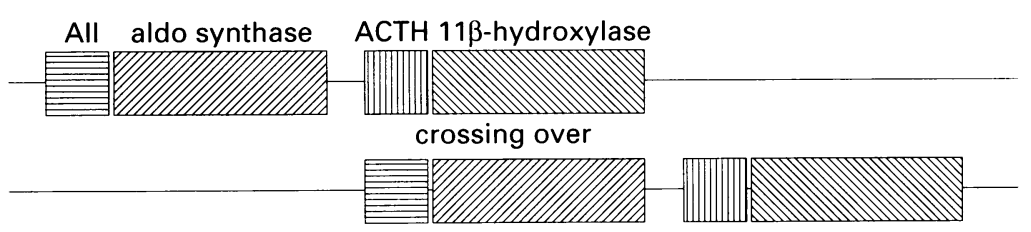

$\Downarrow$

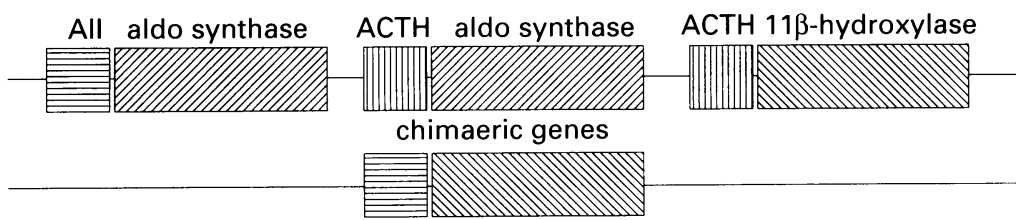

All 11ß-hydroxylase

All=angiotensin II ACTH=adrenocorticotrophic hormone aldo=aldosterone regulatory sequence

Figure 3 Schematic representation of crossing over during meiosis of $11 \beta$-hydroxylase and aldosterone synthase to produce the chimaeric gene tightly linked to GRA.

developed hypokalaemia $(\mathrm{K}+2 \cdot 8 \mathrm{mmol} / \mathrm{l})$ while on thiazide diuretics and required potassium supplementation. In October 1992, he was found to have primary aldosteronism (renin $2 \mu \mathrm{U} / 1$ (NR $5-50 \mu \mathrm{U} / \mathrm{l}$ ), aldosterone $24.9 \mathrm{ng} / \mathrm{dl}(\mathrm{NR}<20)$ ). ECG again showed evidence of left ventricular hypertrophy. Abdominal CT scan showed no evidence of a Conn's adrenal adenoma and the raised aldosterone level was markedly suppressed from around 30 to $2 \mathrm{ng} / \mathrm{dl}$ two days after commencing $0.5 \mathrm{mg}$ twice daily of dexamethasone (fig 5). DNA analysis was then carried out to confirm the clinical diagnosis of GRA. Since the diagnosis of GRA, the addition of dexamethasone to his antihypertensive medication has improved the control of blood pressure and he has been normokalaemic (October 1993, blood pressure $125 / 94 \mathrm{mmHg}$, serum potassium

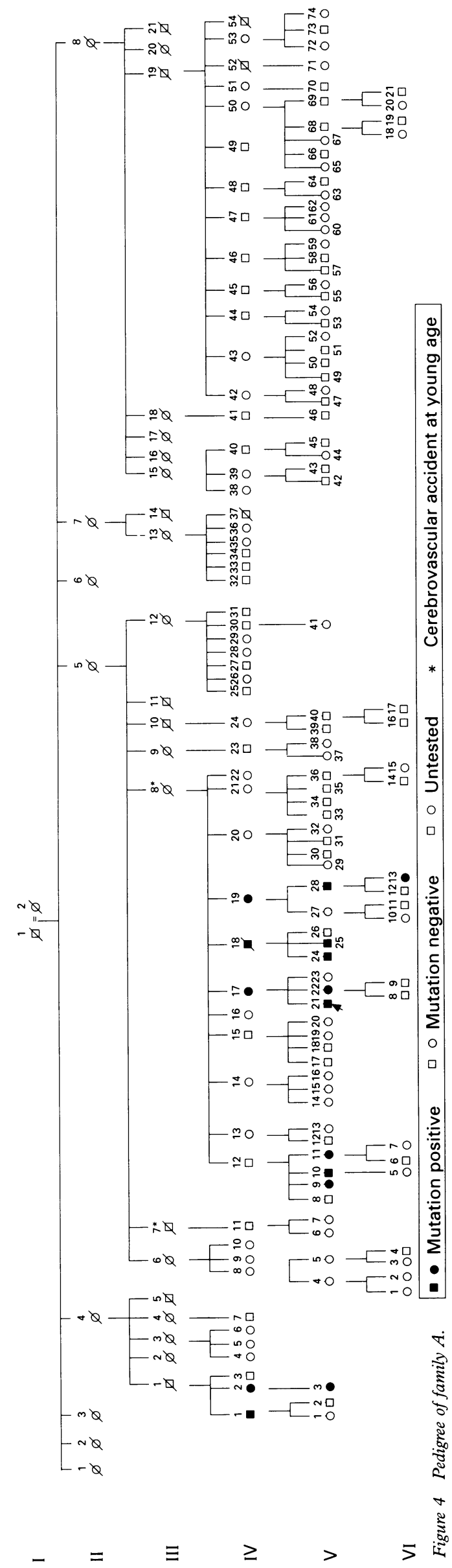




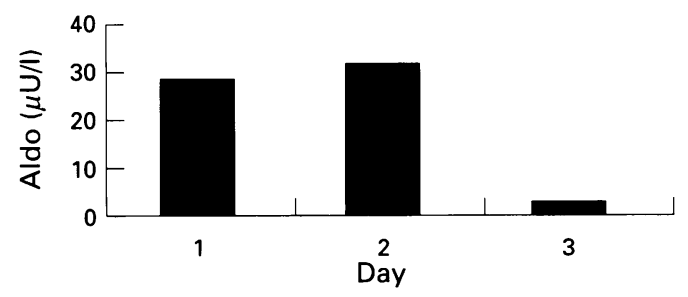

Figure 5 Aldosterone levels after starting oral dexamethasone $0.5 \mathrm{mg}$ twice daily in the proband of family $A$.

$4 \cdot 1 \mathrm{mmol} / \mathrm{l}$ while taking dexamethasone $0.25 \mathrm{mg}$ twice daily, amiloride $10 \mathrm{mg}$ daily, bumetanide $1 \mathrm{mg}$ daily, and quinapril $5 \mathrm{mg}$ daily).

Additional family members were traced from the family history and records of marriages, births, and deaths for individual parishes of north east Scotland. Thirty-seven members of family A have been investigated to date and 15 (including the proband) identified as possessing the chimaeric gene strongly linked to GRA. As can be seen in the table, two family members (IV.19 and V.9) who have the abnormal chimaeric gene have no past medical history of hypertension, normal blood pressure recordings, and normal plasma potassium concentrations. One of these, the proband's 69 year old maternal aunt (IV·19), had a blood pressure of $152 / 88 \mathrm{mmHg}$ and potassium $4.6 \mathrm{mmol} / \mathrm{l}$ at the time of testing.

\section{FAMILY B}

The proband of family B (V.6, fig 6), a 25 year old man, had severe hypertension diagnosed at the age of 15 following a school medical. After admission for blood pressure assessment he was found to have a resting blood pressure of 150/ $114 \mathrm{mmHg}$, serum urea $4.0 \mathrm{mmol} / 1$, and potassium $3.9 \mathrm{mmol} / \mathrm{l}$, and borderline criteria for left ventricular hypertrophy on ECG. There was a strong maternal family history of hypertension in his mother (IV·2), grandmother (III·4), and uncle (IV-3). Despite antihypertensive medication there were problems with control. In 1993 he was noted to have hypokalaemic alkalosis with serum potassium $3.3 \mathrm{mmol} / 1$ and bicarbonate $34 \mathrm{mmol} / \mathrm{l}$ (NR $22-30 \mathrm{mmol} / \mathrm{l}$ ). On further investigation, he was found to have raised plasma aldosterone levels (970, $1350 \mathrm{pmol} / 1$ (NR 100-400 pmol/1)) which was also suppressed to $220 \mathrm{pmol} / 1$ following two days of dexamethasone therapy at the dosage $0.5 \mathrm{mg}$ twice daily. His hypertension has continued to respond to low dose dexamethasone $(0.75 \mathrm{mg}$ daily) and he is normokalaemic (serum

Mutation positive family $A$ members by Southern blotting

\begin{tabular}{llllll}
\hline & Age & Sex & BP* & PMH of HT† & Biochemistry \\
\hline IV.17 & 82 & F & $190 / 116$ & HT aged 40 & Episode of hypokalaemic alkalosis \\
V·21 & 54 & M & $220 / 150$ & HT aged 15 & Hypokalaemic alkalosis on thiazide \\
V.22 & 50 & F & $180 / 104$ & HT aged 17 & Hypokalaemic alkalosis \\
IV.19 & 69 & F & $152 / 88$ & No PMH HT & Normal range \\
V.28 & 43 & M & $160 / 100$ & HT aged 27 & Normal range \\
VI·13 & 14 & F & & No PMH HT & \\
IV.18 & 68 & M & $170 / 120$ & HT aged 35 & Hypokalaemia \\
V.25 & 31 & M & $170 / 114$ & HT aged 15 & Normal range \\
V.24 & 30 & M & & & \\
V·10 & 35 & M & $170 / 110$ & HT aged 27 & Hypokalaemia on thiazide diuretic \\
V.11 & 34 & F & $170 / 102$ & HT aged 33 & Normal range \\
V.9 & 28 & F & $146 / 97$ & No PMH HT & Normal \\
IV·2 & 33 & F & $160 / 100$ & Known HT & Hypokalaemia on thiazide diuretic \\
IV·1 & 35 & M & $176 / 108$ & Known HT & Hypokalaemia on thiazide diuretic \\
\hline
\end{tabular}

* Blood pressure on no antihypertensive treatment.

† Hypertension: sitting blood pressure $>160 / 95 \mathrm{mmHg}$.

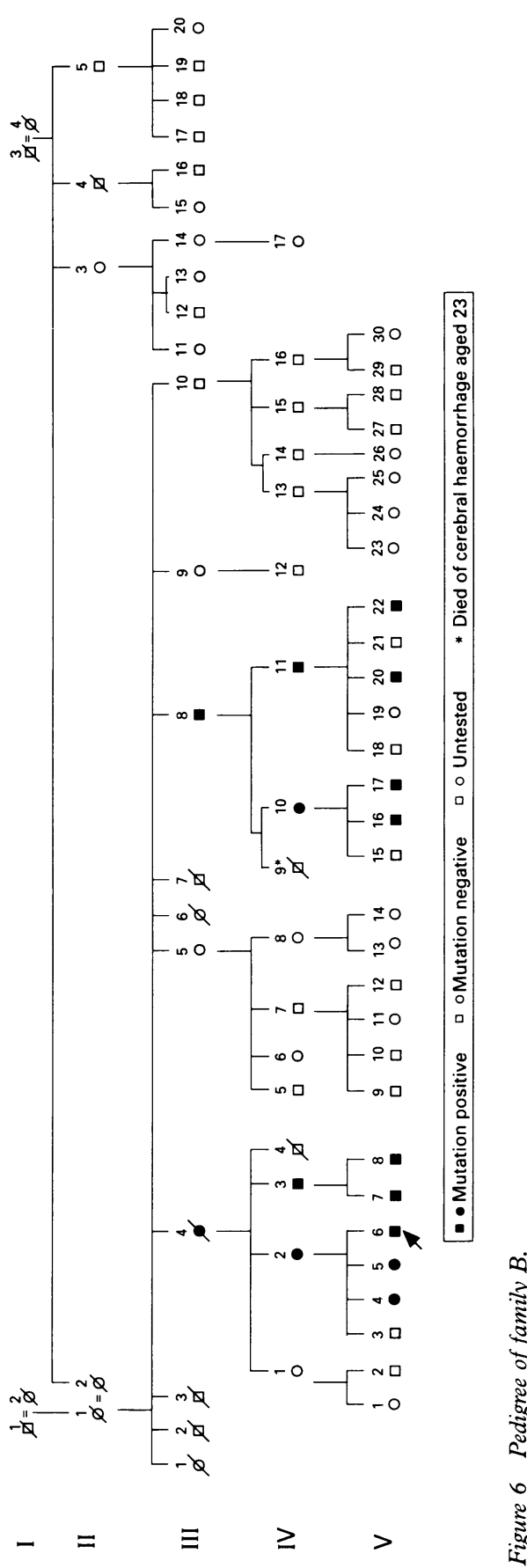

potassium $3.8 \mathrm{mmol} / \mathrm{l})$. Of the 29 additional family members investigated, we have identified a further 14 possessing the abnormal chimaeric gene. Again, there is a spectrum of severity of clinical features; three mutation positive family members by DNA testing had no past medical history of hypertension with normal blood pressure and serum potassium levels while three (IV·10, V·17, V·16) had hypertension diagnosed in their teenage years. 
The variation in phenotype of those having the mutation is illustrated by the immediate family members of the proband of family $B$. His mother (IV-2) was diagnosed as having borderline blood pressures from the age of 19 but was first treated for hypertension aged 28 (BP 150/115 mmHg) and has had normal serum biochemistry. She has been previously treated with a thiazide diuretic and is currently treated with amiloride $5 \mathrm{mg}$ daily with good blood pressure control. The proband has two sisters both possessing the chimaeric gene of GRA on DNA analysis, neither of whom had a past medical history of hypertension. The oldest $(\mathrm{V} \cdot 5)$ is normotensive and has serum potassium within normal limits; the younger sister $(\mathrm{V} \cdot 4)$ had a borderline resting blood pressure but satisfactory daytime mean 24 hour ambulatory blood pressure $(136 / 80 \mathrm{mmHg})$ and has not required therapy. At the time of diagnosis she had a potassium at the lower limit of normal $(3.5 \mathrm{mmol} / \mathrm{l})$.

We are currently investigating a further three families all with a proband found to possess the chimaeric gene tightly linked to GRA. The proband of the third family is a 30 year old man from Peterhead, found on a screening medical to have a raised blood pressure. Initial investigations showed hypokalaemia (serum potassium $3.4 \mathrm{mmol} / \mathrm{l}$ ) and sequelae of hypertension: left ventricular hypertrophy on ECG and grade I hypertensive fundal changes with a strong maternal family history of hypertension (mother, aunt, and two uncles from the mother's four sibs), one of the uncles having died from a cerebral haemorrhage aged 30 . The proband of the fourth family is a 56 year old woman from Huntly who has been treated for hypertension since the age of 27 , who has been on dual therapy of beta blockade and thiazide diuretic, and has had normal biochemistry, normal fundoscopy, and no evidence of left ventricular hypertrophy on ECG, but who had a family history of hypertension and primary aldosteronism in her mother and of two maternal uncles with cerebral haemorrhage.

The proband of the fifth family has had high blood pressure since the age of 28 , is currently treated with triple therapy of atenolol, enalapril, and the thiazide diuretic bendroflurazide, and has had a persistent mild hypokalaemic alkalosis (recent biochemistry potassium $3.6 \mathrm{mmol} / 1$, bicarbonate $32 \mathrm{mmol} / \mathrm{l})$. His mother, aged 74, has hypertension.

\section{Discussion}

As can be seen from the clinical features of the two families presented here, subjects affected with GRA may present with a spectrum of disease with a few having severe hypertension with attendant early morbidity and mortality, primarily because of stroke. Although some of our family members described had evident hypokalaemic alkalosis, in most of the cases hypokalaemia is only apparent when potassium homeostasis is stressed by treatment with thi- azide diuretics. The majority of positive family members are clinically indistinguishable from patients with essential hypertension and in many cases were being treated as such before the diagnosis. Few subjects are normotensive.

This form of hypertension is noteworthy because those with severe hypertension, such as the probands of the two families described, may be unresponsive to standard antihypertensive medication but successfully managed by treatment with appropriate medical therapy such as dexamethasone, spironolactone,$^{214}$ or amiloride. ${ }^{1516}$ Expected benefit from identification and treatment of these cases is therefore high. It is important to identify at risk subjects as they can be monitored and treated appropriately early in life to prevent complications of severe hypertension. Each index case identified has had many affected relatives in whom the aetiology of their hypertension was previously undiagnosed and in whom the blood pressure control may benefit from alternative or additional therapy to the standard antihypertensive medication, such as dexamethasone or anti-mineralocorticoid medication.

We much appreciate the cooperation, help, and interest of the families. We thank Dr N MacKay for his help and advice.

1 New MI, Oberfield SE, Levine LS, et al. Autosomal dominan transmission and absence of HLA linkage in dexatransmission and absence of HLA linkage in dexai: $550-1$.

2 Sutherland DJA, Ruse JL, Laidlaw JC. Hypertension, increased aldosterone secretion and low plasma renin activity relieved by dexamethasone. Can Med Assoc $\mathcal{F}$ 1966;95 1109-19.

3 New MI, Peterson RE. A new form of congenital adrena hyperplasia. F Clin Endocrinol Metab 1967;27:300-5.

4 Miura K, Yoshinaga K, Goto K, et al. A case of glucocorticoidresponsive aldosteronism. F Clin Endocrinol Metab 1968;28 1807-15.

5 Giebink GS, Gotlin RW, Biglieri EG, Katz FH. A kindred with familial glucocorticoid-suppressible aldosteronism. $\mathcal{f}$ Clin Endocrinol Metab 1973;36:715-23.

6 Ganguly A, Grim CE, Bergstein J, et al. Genetic and pathophysiologic studies of a new kindred with glucocorticoid-suppressible hyperaldosteronism manifest in corticoid-suppressible hyperaldosteronism manifest in

$7 \mathrm{Chu}$ MD, Ulick S. Isolation and identification of 18-hydroxychu $M D$, Ulick . Isolation and identification of 18 -hydroxy-
cortisol from the urine of patients with primary hyperaldosteronism. F Biol Chem 1982;257:2218-24.

8 Ulick S, Chu MD, Land M. Biosynthesis of 18-oxocortiso by aldosterone-producing adrenal tissue. $\mathcal{F}$ Biol Chem 1983 258:5498-502.

9 Lifton RP, Dluhy RG, Powers M, et al. A chimaeric $11 \beta$ hydroxylase/aldosterone synthase gene causes glucocorticoid-remediable aldosteronism and human hypertension. Nature 1992;355:262-5.

10 Mornet E, Dupont B, Vitek A, White PC. Characterisation of two genes encoding human steroid $11 \beta$-hydroxylase $(P$ 45011ß). ₹ Biol Chem 1989;264:20961-7.

11 Lifton RP, Dluhy RG, Powers $M$, et al. Hereditary hypertension caused by chimaeric gene duplications and ectopic expression of aldosterone synthase. Nature Genet topic expression

12 Miyahara K, Kawamoto T, Mitsuuchi Y, et al. The chimeric gene linked to glucocorticoid suppressible hyperaldosteronism encodes a fused P-450 protein possessing aldosterone synthase activity. Biochem Biophys Res Commun. 1992;189:885-91.

13 Gomez-Sanchez CE, Gill JR Jr, Ganguly A, Gordon RD Glucocorticoid-suppressible aldosteronism: a disorder of the adrenal transitional zone. $\mathcal{F}$ Clin Endocrinol Metab 1988 67:444-8.

14 Gill JR, Bartter FC. Overproduction of sodium-retaining steroids by the zona glomerulosa is adrenocorticotrophinin 7 Clin Endocrinol Metab 1981; 53:331-7.

15 Kremer D, Boddy K, Brown JJ, et al. Amiloride in the treatment of primary hyperaldosteronism and essential hyment of primary hyperaldosteronism

16 Stockigt JR, Scoggins BA. Long term evolution of glucocorticoid-suppressible hyperaldosteronism. F Clin Endocrinol Metab 1987;64:22-6. 